\title{
Pediatrik Hastalarda Maksiller Sinüs Morfometrisi ile Varyasyonlarının Akut ve Kronik Sinüzitle İlişkisi
}

\author{
The Relation of Maxillary Sinus Morphometry and Its Variations with Acute and Chronic Sinusitis in Pediatric \\ Patients
}

Muhammet Bora UZUNER ${ }^{1}$, Sefer ÜSTEBAY²

\begin{abstract}
ÖZ
Maksiller sinüs doğumda bulunan bilateral en büyük paranazal sinüslerdir. Bu çalışmada retrospektif olarak kranial Magnetik Rezonans Görüntüleme (MRG) sonrası, maksiller sinüs varyasyon sıklığını, patolojilerini ve morfometrik ölçümlerini saptamak, varyasyonların maksiller sinüslerdeki enflamatuar sinüs hastalıklarına predispozisyon oluşturup oluşturmadığının değerlendirilmesi amaçlandı. Çalışmada hastalarda MRG'de; maksiller sinüs'ün coronal kesitte: longitudinal, transvers, sert damağa $(\mathrm{MSOH})$ ve concha nasalis inferior'a (MSOIT) olan uzaklık ölçümleri ve sagittal kesitte; antero-posterior uzunluğu ölçüldü. Maksiller sinüzit tanılı hastalar akut maksiller sinüzit (Grup 1) ve kronik maksiller sinüzit (Grup 2) olarak iki gruba ayrıldı. İstatistiksel analiz SPSS version16 (IBM Corporation) kullanılarak student $\mathrm{t}$ testi ile yapıldı. Çalışmada 105 hastanın 50'si $(\% 47,6)$ erkek, 55'i $(\% 52,4) \mathrm{k} 1 \mathrm{z}$ hasta idi. Hastaların yaş ortalaması Grup 1 için 8,1, Grup 2 için 13,3 idi. Grup 1'de 13 hastada, Grup 2'de 22 hastada olmak üzere toplamda $35(\% 33,3)$ hastada en az bir maksiller sinüs anatomik varyasyonu saptand. Hastaların MRG ile her iki grubun sağ ve sol maksiller sinüs anatomik ölçümlerinin karşılaştırma değerlendirmesinde transvers sol-sağ dışında diğer anatomik ölçümlerde istatiksel olarak anlamlı farklılık bulunmadı. Grup 1'de; MSOH sol-sağ ve MSO sol-sağ ölçüm değerlendirmesinde her iki parametrede sol maksiller sinüs ölçümleri daha uzun olup, istatiksel olarak anlamlı bir fark tespit edildi ( $\mathrm{p}<0,05)$. Grup 2'de; sağsol taraf maksiller sinüs anatomik ölçüm karşılaştırma sonuçlarında anlamlı istatistiksel fark olmadığı tespit edildi. Çalışmamızda septal deviasyon $(\% 12,4)$ en fazla görülen anatomik varyasyondu. Çalışmamızda hastalar arasında maksiller sinüs morfometrisinde farklılıklar olsa da sinüzit oluşumuna etkisi kesin olmayıp bazı anatomik varyasyonların özellikle kronik maksiller enfeksiyon oluşumuna yatkınlık oluşturabileceği düşünülmüştür.
\end{abstract}

Anahtar Kelimeler: Anatomik Varyasyon, Maksiller Sinüs, Sinüzit

\begin{abstract}
The bilateral maxillary sinus is the largest paranasal sinus present at birth. This study aims to retrospectively determine the frequency of its variations, pathologies and morphometric measurements following patients' cranial Magnetic Resonance Imaging and evaluate whether the variations predispose patients to inflammatory sinus diseases. We took the longitudinal and transverse measurements of the ostium's distance to the hard palate (MSOH) and inferior concha nasalis (MSOIT) in the coronal section and the antero-posterior length in the sagittal section of the maxillary sinus. Patients with maxillary sinusitis were divided into Group 1 (mean age 8.1): Acute Maxillary Sinusitis and Group 2 (mean age 13.3): Chronic Maxillary Sinusitis. The student t-test in SPSS was used for the statistical analysis. 50 out of 105 patients were males (\%47.6) and 55 (\%52.4) females. At least one maxillary sinus anatomical variation was detected in 35 patients (\%33): 13 in Group 1 and 22 in Group 2. No statistically significant difference was found between the right and left maxillary sinus measurements, except for the transverse left-right. In Group 1, left maxillary sinus measurements were longer in $\mathrm{MSOH}$ left-right and MSO left-right comparisons and the difference was statistically significant $(p<0,05)$. No significant difference was found in the right-left maxillary sinus measurements in Group 2. Septal deviation was the most commonly observed anatomical variation (\%12.4). Although there were differences in the patients' maxillary sinus' morphometry and while their impact on sinusitis formation is uncertain, it is thought that some anatomical variations can predispose patients particularly to chronic maxillary infection.
\end{abstract}

Keywords: Anatomical Variation, Maxillary Sinus, Sinusitis

\footnotetext{
Etik Kurul No: 80576354-050-99/135

${ }^{1}$ Dr. Öğretim Üyesi, Muhammet Bora UZUNER, Anatomi, Bandırma Onyedi Eylül Üniversitesi Tıp Fakültesi, borauzuner1@hotmail.com, ORCID: 0000-0001-6557-3086

${ }^{2}$ Dr. Öğretim Üyesi, Sefer ÜSTEBAY, Çocuk Sağlığı ve Hastalıkları, Bandırma Onyedi Eylül Üniversitesi Tıp Fakültesi, ustabay_dr@hotmail.com, ORCID: 0000-0003-1507-5921

İletişim / Corresponding Author: Muhammet Bora UZUNER

Geliş Tarihi / Received: $\quad 28.01 .2021$

e-posta/e-mail:

borauzuner1@hotmail.com

Kabul Tarihi/Accepted: $\quad 04.04 .2021$
} 


\section{GİRIŞ}

Paranazal sinüsler (maksiller, etmoid, frontal ve sfenoid) simetrik, iç yüzeylerinde silialı kolumnar epitel olan ve hava ile dolu boşluklardır. Etmoid ve maksiller sinüsler de yenidoğan döneminde, sfenoid sinüsler de beş yaş civarında, frontal sinüsler de ise 6-8 yaş civarında havalanma saptanır. Sinüsler çocukluk çağı boyunca gelişir ve adolesanlarda erişkin boyutlarına ulaşır. Paranazal sinüsün müköz membranının enflamasyonu sinüzit olarak adlandırılır. ${ }^{1-4}$

Paranazal sinüsler, çocukluk döneminde erişkinlere göre hacim bakımından küçük olduğundan paranazal sinüs hastalıkları sıklıkla görülmektedir. Maksiller sinüsler en büyük bilateral paranazal sinüslerdir ve burun boşluğunun orta bölümüne tek veya çoklu ostium ile açılır. Çocukluk ve erişkin döneminde maksiller sinüs genişlik ve şekil açısından farklılıklar göstermekte ve maksiller sinüs enfeksiyonu siklikla karşımıza çıkmaktadır., ${ }^{5,6}$ Ayrıca maksiller sinüs havalanmasını etkileyen bazı anatomik varyasyonlar (nazal septum deviasyonu, nazal polip, koanal atrezi), burun içerisinde yabanc1 cisim, adenoid vejetasyon, tonsil hipertrofisi gibi nazal havayolunu etkileyen obstrüksiyon ve staz durumlarının tekrarlayan sinüzit oluşumuna yatkınlık oluşturduğu bilinmektedir. ${ }^{6-8}$
Çocukluk döneminde sinüzit tanısı genellikle klinik bulgularla konmaktadir. Akut bakteriyel sinüzit; semptom ve bulguların 4 haftadan az devam ettiği, kronik sinüzit ise; semptom ve bulgularin 12 haftadan fazla sürdüğü bakteriyel enfeksiyondur. Sinüzit patojenin kaynağı ve altta yatan duruma göre nazokomiyal, immün yetmezlikli ve diş kaynaklı sinüzit olarak da sinıflandirılabilir., ${ }^{2,9-11}$

Çocuklarda sinüzitin doğru tedavisi için etyolojik neden ortaya konmal1, tedaviye dirençli veya tekrarlayan sinüzit öyküsü olan, sinüzit tanısı şüpheli olan, anatomik varyasyon düşünülen ya da komplikasyon geliştiği düşünülen hastalarda radyolojik görüntülemelerden yararlanılmalıdır.

$\mathrm{Bu}$ çalışmada retrospektif olarak cranial Magnetik Rezonans Görüntülemesi (MRG) olan ve eş zamanlı maksiller sinüzit tanısı alan çocuklarda; anatomik varyasyonların sıklığını ve patolojilerini saptamak, osteomeatal kompleksin radyolojik ölçümlerinin değerlendirilmesi ve bu ölçüm sonuçlarının maksiller sinüslerdeki enflamatuar sinüs hastalıklarına predispozisyon oluşturup oluşturmadığının değerlendirilmesi amaçlandi.

\section{MATERYAL VE METOT}

2015-2021 tarihleri arasında Kafkas Üniversitesi Tıp Fakültesi Çocuk Sağlığı ve Hastalıkları Ana Bilim Dalı'nda MRG yapılmış akut-kronik maksiller sinüzit tanılı toplam 105 çocuk hasta çalışmaya dahil edildi.

Hasta dosya arşiv kayıtları ve MRG radyoloji raporları incelendi. Maksiller sinüs anatomik parametre ölçümleri aynı anatomist tarafindan ölçüldü. Hastalar akut maksiller sinüzit (Grup 1) ve kronik maksiller sinüzit (Grup 2) tanılarına göre iki gruba ayrıldı.

Çalışmada sagittal ve coronal kesitli MRG olan maksiller sinüzit tanılı hastalarda maksiler sinüsün coronal kesitte: longitudinal (A), transvers (B) en uzak mesafeleri, maksiler sinüsün sert damağa $(\mathrm{MSOH})$ ve concha nasalis inferior'a (MSOIT) olan uzaklık ölçümleri ve sagittal kesitte; anteroposterior yönde en uzak mesafesi (C) ölçüldü (Resim1). 


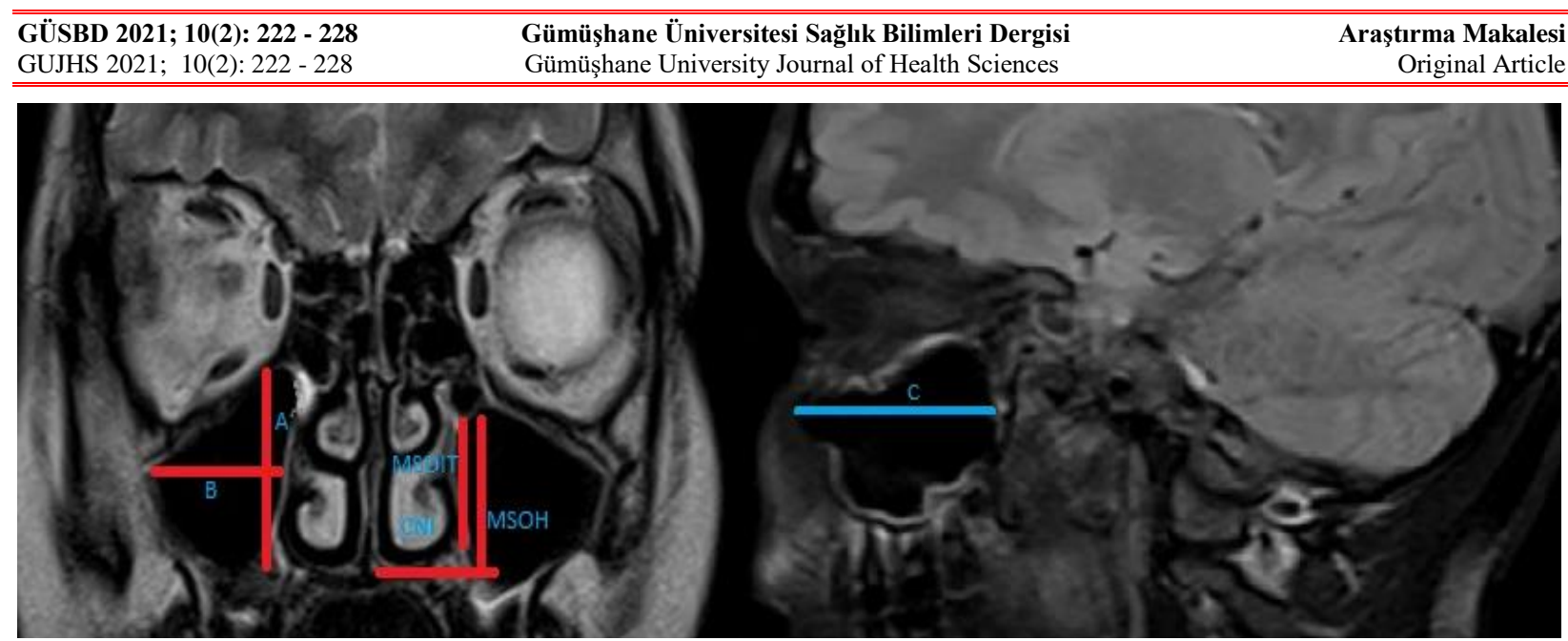

Resim 1. A: Maksiller sinüs longitudinal ölçümü, B: Maksiller sinüs transvers ölçümü, C: antero-posterior yönde en uzak mesafesi, MSOIT: maksiller sinüs ostium'unun concha nasalis inferior'a olan uzaklığı, MSOH: maksiller sinüs ostium'unun sert damağa uzaklığı, CNI: concha nasalis inferior.

Maksiller sinüs bölgesini etkileyecek herhangi bir cerrahi veya dental girişim öyküsü olan, travma öyküsü olan hastalar ile MRG'leri olmayan hastalar çalışmaya alınmadı. Ayrıca öyküsünde maksiller sinüs enfeksiyonuna yatkınlık oluşturacak maksillo-facial anomalisi olan ve sistemik bir hastalığı olan çocuklar çalışma dişı bırakıldı.

\section{MR Görüntüleme ve Değerlendirme}

MR görüntülemeleri Magnetom Essenza 1,5T MRG cihazı (Siemens Healthcare $\mathrm{GmbH}$, Erlangen, Germany) ile çekilmiş olup, tüm ölçümler cihazla entegre PACS sistemi üzerinde yapıldı. Kranial MRI çalışmalarını gerçekleştirmek için 1,5-T MRI cihazı (Siemens Magnetom Essenza; Siemens; Erlangen, Almanya) kullanıldı. Kranial MRI görüntülerini elde etmek için kuadratür bobinler kullanıldı. Tarama dizisi Sagital T1WI (TE (time of echo) 7,8 - 8,5 ms, TR (time of repetition) 450-2000 ms, dilim kalınlığ $8 \mathrm{~mm}$ ), T2WI (TE 92-98 ms, TR $3800-6000 \mathrm{~ms}$ ), T1WI (TE 7,5-8,5 ms, TR 400-6000 ms, dilim kalınlığ 5 mm), FLAIR (TE 794-109 ms, TR 8500-9000 ms, dilim kalınlığ $5 \mathrm{~mm}$ ) ve DWI (TE 75-86 ms, TR 3100-6400 ms, dilim kalınlığı $5 \mathrm{~mm}$ ). Sagittal ve coronal MRG'lerinin yorumlanmasında maksiller sinüsler iki ayrı taraf (sağ-sol) olarak kabul edildi. Maksiller ve nazal değerlendirmelerde maksiller sinüste septa, aksesuar maksiller sinüs ostium'u, hipoplazik maksiller sinüs, maksiller kist, maksiller polip, nazal septum deviasyonu, nazal polip, superior konka bülloza ve orta konka bülloza değerlendirildi.

Tüm ölçüm analizleri SPSS version 16 (IBM Corporation) kullanılarak yapıldı. İstatistiksel analiz Student $t$ testi ile gerçekleştirildi. Her bir grup için maksiler sinüs ve nazal kavite anatomik varyasyonlarının dağılımı hesaplandı. Verilerin değerlendirilmesinde sayı ve yüzde oranı ile ifade edildi. Sonuçlar $\% 95$ güven aralığında, $\mathrm{p}<0,05$ anlamlılık düzeyine göre değerlendirildi.

\section{Araştırmanın Etik Yönü}

Çalışma için Kafkas Üniversitesi Tıp Fakültesi yerel etik kurulundan 06.05.2020 tarih ve 80576354-050-99/135 say1l etik kurul onayı alındı. Çalışmanın yapılacağı Kafkas Üniversitesi Tıp Fakültesi Çocuk Sağlığı ve Hastalıkları Ana Bilim Dalı Başkanlığı'ndan retrospektif çalışmanın yapılabilmesi için izin alındı. Katılımcıların kişisel bilgileri ve çalışma verileri Helsinki Bildirgesi'ne göre toplandi.

\section{Araştırmanın Kısıtlılıkları}

Çocukluk çağında herhangi bir klinik zorunluluk olmadıç̧a paranasal sinüs değerlendirmelerinde radyolojik görüntülemeler (BT-MRG) tıbbi açıdan kullanılmamaktadır. Çocukluk çağında MRG çekimi uzun ve anestezik ilaç uygulaması gerektirebileceğinden sağlıklı çocuklarda bu çalışma için kontrol grubu eklenmemiştir. 


\section{BULGULAR VE TARTIŞMA}

Çalışmaya alınan 105 hastanın 50'si $(\% 47,6)$ erkek, 55'si $(\% 52,4) \mathrm{k1z}$ hasta idi. Hastaların yaş aralığ 1 ortalaması Grup 1 için $8,1 \pm 3,9 /$ yll ve Grup 2 için 13,2 $\pm 3,2 /$ yll idi. Gruplardaki hastalara ait anatomik ölçümlerin cinsiyet yönünden değerlendirilmesinde istatistiksel fark saptanmad $1 \quad(p>0,05)$. Olgularımızın 55'i (Grup 1) akut maksiller sinüzit, 50'si (Grup 2) kronik maksiller sinüzit tanılı olup Grup 1 'de 13, Grup 2'de 29 anatomik varyasyon olduğu saptandı. Toplamda $34 \quad(\% 32,3)$ hastada en az bir maksiller sinüs ve/veya nazal kavite anatomik varyasyonu, 71 $(\% 67,7)$ hastada herhangi bir anatomik varyasyon saptanmadi. Olgularda maksiller sinüs anatomik varyasyon sıklığ 1 ; Grup 1 de; $2(\% 3,6)$ hipoplazik maksiller sinüs, $1(\% 1,8)$ maksiller kist, $1(\% 1,8)$ maksiller polip, 4 $(\% 7,2)$ nazal septum deviasyonu, $1(\% 1,8)$ nazal polip, $4(\% 7,2)$ konka bülloza saptand1. Ayrica 1 vakada en az 2 anatomik varyasyon birlikteliği, 3 hastada da ayrıca preseptal sellülit mevcuttu. Grup 2'de ise 1 (\%2) maksiller sinüste septa, $1(\% 2)$ aksesuar maksiller sinüs ostiumu, $4(\% 8)$ maksiller kist, 3 (\%6) maksiller polip, 9 (\%18) nazal septum deviasyonu, 4 (\%8) nazal polip, (\%14) konka bülloza saptandı. Ayrıca 6 hastada en az 2 anatomik varyasyon birlikteliği ve 1 hastada da preseptal sellülit mevcuttu. Sağ-sol maksiller sinüs anatomik ölçümlerin arasında her iki grup içinde tüm parametrelerde istatistiksel fark bulundu $(\mathrm{p}<0,05)$.

(Tablo1)

Tablo 1. Sağ-Sol Maksiller Sinüs Anatomik Ölçümleri Arasındaki İstatistiki Değerlendirmeler

\begin{tabular}{|c|c|c|c|}
\hline & \multicolumn{3}{|c|}{$95 \% \mathrm{GA}$} \\
\hline & $\mathrm{p}^{*}$ & Alt Değer & Üst Değer \\
\hline Cinsiyet & 0,116 & $-0,345$ & 0,039 \\
\hline A-SAĞ & $\mathbf{0}$ & $-8,74268$ & $-2,9546$ \\
\hline A-SOL & $\mathbf{0}$ & $-8,66864$ & $-3,09193$ \\
\hline B-SOL & 0,006 & $-4,52333$ & $-0,76902$ \\
\hline B-SAĞ & $\mathbf{0 , 0 3 7}$ & $-4,58205$ & $-0,14935$ \\
\hline C-SAĞ & $\mathbf{0}$ & $-6,21177$ & $-2,20773$ \\
\hline C-SOL & 0,003 & $-6,63418$ & $-1,37126$ \\
\hline MSOH-SAĞ & $\mathbf{0}$ & $-5,62619$ & $-2,18941$ \\
\hline MSOH-SOL & $\mathbf{0 , 0 0 1}$ & $-5,32523$ & $-1,4998$ \\
\hline MSOIT-SAĞ & $\mathbf{0}$ & $-6,25018$ & $-2,88828$ \\
\hline MSOIT-SOL & $\mathbf{0}$ & $-5,42481$ & $-2,1234$ \\
\hline
\end{tabular}


Hastaların MRG ile her iki grubun kendi içerisinde sağ ve sol maksiler sinüs anatomik ölçümlerinin karş1laştırma değerlendirmesinde Grup 1 için sadece maksiller sinüs anatomik ölçümlerinden MSOH sol-sağ ile MSOIT sol-sağ arasında anlamlı bir fark tespit edildi. Grup 2'de; sağsol taraf maksiller sinüs anatomik ölçüm karşılaştırma sonuçlarının hiçbirinde anlamlı istatistiksel fark olmadığı tespit edildi. (Tablo 2) Çalışmamızda Grup 1 ve Grup 2'de maksiller sinüs anatomik ölçüm sonuçları cinsiyet açısından karşılaştırılmış olup Grup 2 için istatistiksel farkl1lık saptanmıştır $(\mathrm{p}<00,5)$.

Tablo 2. Grup İçi Anatomik Ölçümlerin Karşılaştırılması

MSOIT sol-MSOIT

\begin{tabular}{|c|c|c|c|c|c|c|}
\hline Grup & & - MSOH sağ & sağ & B Sağ -B Sol & A Sol-A Sağ & C Să̆-C Sol \\
\hline 1 & $\mathrm{p}^{*}$ & 0,004 & 0,002 & 0,479 & 0,207 & 0,186 \\
\hline 2 & $\mathrm{p}^{*}$ & 0,577 & 0,859 & 0,612 & 0,176 & 0,935 \\
\hline
\end{tabular}

$\mathrm{p}^{*}:$ Asymp.Sig.(2-tailed)

Çocukluk döneminde paranazal sinüs gelişimi genellikle 12 yaş dolaylarında erişkin düzeyine ulaşmaktadır. Genellikle 6-8 yaşından sonra paranazal sinüslerde anatomik varyasyonların görülme sıklığı artmaktadır. Anatomik varyasyonların çocuklarda insidansı ile ilgili araştırmalar ve bu araştırmalarda varyasyonların sıklığı ile ilgili farklı sonuçlar mevcuttur. ${ }^{12-14,23.24}$ Çocuklarda yapılan paranazal sinüs anatomik varyasyon sıklığı çalışmalarında; Eryılmaz ve ark. $^{12}$ büyük çocuklarda anatomik varyasyonlara küçük çocuklara göre daha sık rastlandığını bildirmişlerdir. Yaptıkları çalışmada, özellikle septal deviasyon, konka bulloza ve agger nazi hücresi büyük çocuklarda daha fazla görüldüğünü raporlamışlardır. Sivaslı ve ark. ise en sık konka bülloza sonra sira ile haller hücresi ve agger nazi hücresi, Kim ve ark. ise en sik agger nazi ve daha sonra septal deviasyonu, Palabıyık en sık septal deviasyon ve konka büllozanın bu dönemde görülen en sik anatomik varyasyon olarak raporlamışlardır. ${ }^{13-15}$ Pediatrik dönem dışında da septal deviasyon ve konka bülloza oranlarının erişkin dönemde de yüksek oranlarda olduğunu gösteren benzer çalışmalar mevcuttur. ${ }^{16,17}$

Septal deviasyon insidansı yapılan çalışmalarda yaşın artması ile birlikte artmaktadır. Çocuklarda daha çok travma, gelişimsel sorunlar, parmakla burun karıştırma ve ağızdan solumaya bağlı gelişebilir. Nazal kaviteyi daraltması sinüzit oluşma riskini arttırmaktadır. Bu çalışmada Septal deviasyon oranlarını literatürle uyumlu şekilde yaş ortalamasının artmasıyla sıklığında artış olduğunu saptadık fakat literatür oranlarının aksine daha düşük oranlarda; Grup 1 için \%5,4 ve Grup 2 için $\% 10$ olarak saptadik. $\mathrm{Bu}$ sonucun hasta gruplarımızın yaş ortalamasının düşük olması nedeniyle olduğunu düşünmekteyiz. Orta konkanın pnömotize olması ile oluşan konka bülloza; lamellar, kistik ve miks olmak üzere üç tiptir. Konka bülloza orta meatusu tıkayarak maksiller ve etmoid sinüzite neden olabilir.

$\mathrm{Bu}$ çalışmada incelenen vakaların $\% 12,4$ 'ünde septal deviasyon bulunmuş olup April ve ark. ile Willner ve ark.'nın çalışmasıyla benzerlik olduğu görüldü. Ayrıca vakaların \%10,5'inde konka bülloza varlığı saptanmış olup literatür çalışmalarına oranla farklılıklar olduğu görüldü. . $\mathrm{Bu}$ çalışmanın literatürdeki diğer çalışmalarla farklılıkların olmasının sebebinin 1rksal, genetik ve yaş ortalaması değișkenliklerinden dolayı olduğu düşünülmektedir. (Tablo 3). 
Tablo 3. Çocuk Çalışmalarında Bildirilen Paranazal Sinüs Ve Nazal Kavitenin Anatomik Varyasyonların Dağılımı ${ }^{12-15}$

\begin{tabular}{|c|c|c|c|c|c|c|c|c|c|c|}
\hline & $\begin{array}{l}\text { Sivaslı } \\
\text { et all. } \\
(2003)\end{array}$ & $\begin{array}{c}\text { Eryılmaz } \\
\text { et all. } \\
(2004)\end{array}$ & $\begin{array}{c}\text { Al- } \\
\text { quadih } \\
\text { et all. } \\
\text { (2008) }\end{array}$ & $\begin{array}{l}\text { Kim et } \\
\text { all. } \\
(2006)\end{array}$ & $\begin{array}{l}\text { April } \\
\text { et all. } \\
\text { (1993) }\end{array}$ & $\begin{array}{c}\text { Willner } \\
\text { et all. } \\
\text { (1997) }\end{array}$ & $\begin{array}{c}\text { Lusk } \\
\text { at all. } \\
(1996)\end{array}$ & $\begin{array}{c}\text { Milczuk } \\
\text { et. all. } \\
\text { (1993) }\end{array}$ & $\begin{array}{c}\text { Palabiyık } \\
\text { (2018) }\end{array}$ & $\begin{array}{c}\mathrm{Bu} \\
\text { çalışm } \\
\mathrm{a}\end{array}$ \\
\hline $\mathbf{n}$ & 47 & 44 & 65 & 13 & 62 & 91 & 15 & 14 & 105 & 105 \\
\hline $\begin{array}{c}\text { Septal } \\
\text { deviasyon } \\
\% *\end{array}$ & - & 40,9 & 18 & 4,3 & 13 & 13 & 0,4 & - & 53 & 12,4 \\
\hline $\begin{array}{c}\text { Konka } \\
\text { bülloza } \\
\% *\end{array}$ & 58 & 29,5 & 51 & 2,7 & 24 & 16 & 0 & 9,6 & 37 & 10,5 \\
\hline
\end{tabular}

Çocuklarda sinüzit oluşumunda çevresel ve sistemik nedenlerin major etkisi bilinmektedir ve literatür çalışmalarında anatomik varyasyonların net etkisi ortaya konmamıştır. ${ }^{12-15} \mathrm{Bu}$ çalışmada da maksiller sinüzit oluşumunda anatomik varyasyonların net rolü olduğu saptanmamıştır fakat anatomik varyasyonlarla sinüzit arasında ilişki olduğu açıktır. Özellikle kronik sinüzit vakalarında bu ilişkinin daha çok olduğu bu çalı̧̧ma sonuçlarında gösterilmiştir. Ayrıca bu çalışmada benzer konuda yapılmış çalışmaların aksine özellikle sinüs gelişiminin tam olarak tamamlanmadığ 8 yaş altında hastalarımızın çok olması nedeniyle literatüre katkı sağlayacaktır. Maksiller sinüs anatomisi bireyler arasında değişkenlik göstermektedir. Aynı kişide iki taraf arasındaki yapı açısından önemli farklılıklar da olabilir. ${ }^{18,19}$ Maksiller sinüs boyutlarını çevresel faktörler, genetik hastalıklar ve enfeksiyonların etkileyebileceği gösterilmiştir. ${ }^{20}$ Çalışmada akut ve kronik maksiler sinüzit enfeksiyonunun maksiller sinüs anatomik ölçümlerinin karşılaş̧ırma değerlendirmesinde istatistiksel olarak anlamlı farklılık tespit edildi. Grup 1'de maksiller sinüs sol-sağ MSOH ve MSOIT anatomik ölçümlerinde istatistiksel olarak anlamlı fark tespit edildi. Grup 1 içindeki diğer maksiller sinüs anatomik ölçümlerinin sağ-sol maksiller sinüs karşılaştırma sonuçlarında anlamlı istatistiksel fark bulunmadı. Yapmış olduğumuz bu çalışmada Grup 2'deki maksiller sinüs anatomik ölçümlerinin hiçbirinde sağ-sol maksiller sinüs karșılaștırma sonuçlarında anlamlı istatistiksel fark bulunmadı. Maksiller sinüs anatomik ölçümlerimizdeki istatistiksel farkl1lıklar Grup 1 ve Grup 2 arasındaki yaşlar arasındaki farklılığın maksiller sinüs gelişimine olan etkisi olduğunu düşünmekteyiz. Maksiller sinüsün adli tıpta cinsiyet tayini nedeniyle değerlendirildiğ çalışmalar mevcuttur. ${ }^{21,22} \mathrm{Bu}$ çalışmada maksiler sinüs anatomik ölçüm boyutlarının cinsiyet açısından değerlendirilmesinde anatomik ölçüm sonuçlarında Grup 1 içinde anlamlı farklılık tespit edilmezken Grup 2 içinde istatistiksel olarak anlamlı farkll1lk tespit edildi. Maksiller sinüsün cinsiyet tayininde kullanıldığ 1 çalışmalarda doğruluk oranının düşük olması ile birlikte $(<\% 70)$ mevcut değerlendirmeler erişkin hastalar düzeyindedir. ${ }^{22} \mathrm{Bu}$ çalışmada pediatrik popülasyondaki hastalarımızdan sadece Grup 2 içinde anlamlı fark bulunması maksiller sinüs gelişiminin bu grupta tamamlanmış olmasına bağlanabilir. 


\section{SONUÇ VE ÖNERILER}

Erişkin hastaların dışında çocukluk döneminde de maksiller sinüs anatomik varyasyonları sıklıkla görülebilmekte ve sinonazal hastalıkların oluşmasına zemin hazırlayabilmektedir. Maksiller sinüzitte; medikal tedaviye dirençli, komplikasyon ve cerrahi müdahale düşünülen veya şüpheli tanilarda

kullanılan

radyolojik görüntülemelerde anatomik varyasyonlar ve maksiller sinüs anatomik ölçüm sonuçlarının değerlendirilmesi tanı ve tedavi için önemli olduğu kadar olası cerrahi müdahalede cerrahi sonuçlarının daha iyi olmasını ve komplikasyonların azalmasını sağlayacaktır.

\section{KAYNAKLAR}

1. Kazkayası, M, Karadeniz, Y. ve Koc, C. (2001). "Cocukların Paranazal Sinüs Bilgisayarlı Tomografilerinde Patolojik Bulgular”. KBB ve BBC Dergisi, 9, 125-128.

2. Cengiz, A.B. ( 2009). Çocuklarda Sinüzit. Çocuk Enfeksiyon Dergisi, 3 (Özel Sayı 1), 35-8.

3. Sentürk, M, Azgin, I, Öcal R, Sakarya, E.U, Güler, I, Övet G. and Tolu, İ. (2015). "Volumetric Analysis of The Maxillary Sinus in Pediatric Patients with Nasal Septal Deviation". ENT Updates, 5 (3), 107-112.

4. Uygur, K, Doğru, H, Döner, F. and Kılıçkaya, M. (1998). "The Role of Adenoid Hypertrophy in Pediatric Chronic Sinusitis". $\mathrm{KBB}$ ve BBC Dergisi, 6 (3), 113-15.

5. Souza, A.K.V, Rajagopal, Ankolekar, V.H, Souza, A.S. and Kotian, R.S. (2016). "Anatomy of Maxillary Sinus and its Ostium: A Radiological Study Using Computed Tomography". CHRISMED J Health Res, 3, 37-40.

6. Manning, S.C. (1993). "Pediatric sinusitis. Otolaryngologic Clinics of North America”, 26 (4), 623-638.

7. Önerci, M. (1996). "Paranazalsnüslerin Anatomisi ve Histolojisi. In. Endoskopik Sinüs Cerrahisi”. Kutsan Ofset, Ankara, 1. Baskı, Bölüm 1, 1-12.

8. Parsons, D.S. (1996). "Chronic Sinusitis: A Medical or Surgical Disease?”. Otolaryngologic Clinics of North America, 29 (1), 1-9

9. Brook, I. (2009). "Sinusitis. Perıodontol 2000", Printed in Singapore. 49:126-39.

10. American Academy of Pediatrics. (2001). "Clinical Practice Guideline: Management of Sinusitis. Pediatrics”, 108 (3), 798808.

11. Novembre, E, Mori, F, Pucci, N, Bernardini, R, Vierucci, A. and Martino, M. D. (2007). "Systemic Treatment of Rhinosinusitis in Children”. Pediatric Allergy and Immunology, $18,56-61$

12. Eryilmaz, A, Göçer, C, Dursun, E, Korkmaz, ., Akmansu, H. and Boynueğri, S. (2004). "The Incidence of Anatomic Variations and Sinus Opacities in Pediatric Patients with Chronic Sinonasal Symptoms". Kulak Burun Bogaz Ihtis Derg, $13(5-6), 116-121$
13. Sivaslı, E, Sirikçi, A, Bayazýt, Y, Gümüsburun, E., Erbagci, H, Bayram, M. ve Kanlýkama, M. (2002). "Anatomic variations of the Paranasal Sinus Area in Pediatric Patients With Chronic Sinusitis”. Surgical and Radiologic Anatomy, 24 (6), 399-404.

14. Jun, Kim, H, Jung Cho, M, Lee, J.W, Tae Kim, Y, Kahng, H, Sung Kim, H. and Hahm, K.H. (2006). "The Relationship Between Anatomic Variations of Paranasal Sinuses and Chronic Sinusitis in Children". Acta oto-laryngologica, 126 (10), 1067-1072.

15. Palabiyik, F. (2018). "Imaging of the Anatomic Variations and Dangerous Areas of The Paranasal Sinuses and Nasal Cavity in Pediatric Patients". İstanbul Kanuni Sultan Süleyman Tıp Dergisi (IKSST), 10 (1), 36-42.

16. Özdemir, M. and Kavak, R.P. (2019). "Assessment of the superior turbinate pneumatization and concomitant nasal pathologies on computed tomography". Journal of Surgery and Medicine, 3 (6), 452-455

17. Salcan, I. and Olgun, A. (2020). "Is There a Relationship Between Epitaxis and Anatomical Variations?". The Eurasian Journal of Medicine, 52 (2), 136.

18. Miller, A.J. and Amedee, R.G. (1997). "Functional Anatomy of the Paranasal Sinuses". The Journal of the Louisiana State Medical Society: official organ of the Louisiana State Medical Society, 149 (3), 85-90.

19. Amedee, R. (1993). "Sinus Anatomy and Function". In: Bailey, B.J. (Ed.). Head and Neck Surgery Otolaryngology. Vol. 1. Philadelphia: J.B. Lippincott Company, p.342-49.

20. Karakas, S. and Kavaklı, A. (2005). "Morphometric Examination of The Paranasal Sinuses and Mastoid Air Cells Using Computed Tomography". Annals of Saudi Medicine, 25 (1), 41-45.

21. Uthman, A.T, Al-Rawi, N.H, Al-Naaimi, A.S. and Al-Timimi, J. F. (2011). "Evaluation of Maxillary Sinus Dimensions in Gender Determination Using Helical CT Scanning". Journal of Forensic Sciences, 56 (2), 403-408.

22. Teke, H.Y, Duran, S, Canturk, N. and Canturk, G. (2007). "Determination of Gender By Measuring The Size of The Maxillary Sinuses in Computerized Tomography Scans". Surgical and Radiologic Anatomy, 29 (1), 9-13. 